\title{
One size does not fit all: HIV prevalence and correlates of risk for men who have sex with men, transgender women in multiple cities in Papua New Guinea
}

Avi J. Hakim ${ }^{1 *}$ D, Kelsey Coy ${ }^{1}$, Steven G. Badman², Barne Willie ${ }^{3}$, Rebecca Narokobi ${ }^{3}$, Josephine Gabuzzi ${ }^{3}$, Simon Pekon ${ }^{4}$, Martha Kupul ${ }^{3}$, Parker Hou ${ }^{3}$, Herick Aeno ${ }^{3}$, Ruthy Neo Boli ${ }^{3}$, Joshua Nembari ${ }^{3}$, Sophie Ase ${ }^{3}$, Angelyne Amos ${ }^{3}$, Nick Dala ${ }^{4}$, Damian Weikum', Steven Callens', John M. Kaldor ${ }^{2}$, Andrew J. Vallely ${ }^{2,3}$, Angela Kelly-Hanku, ${ }^{2,3}$ and on behalf of the Kauntim mi tu Study Team

\begin{abstract}
Background: Biobehavioral data about men who have sex with men (MSM) and transgender women (TGW) in Papua New Guinea (PNG) are limited to those who sell sex. Information about those MSM and TGW who do not sell sex is necessary to guide HIV prevention and treatment efforts.
\end{abstract}

Methods: We conducted respondent-driven sampling (RDS) surveys among MSM and TGW in Port Moresby, Lae, and Mt. Hagen, PNG from in 2016 and 2017. Eligibility criteria was: aged $\geq 12$ years, born male, could speak English or Tok Pisin and had oral or anal sex with another person born male in the past 6 months. Participants were interviewed face-to-face and offered rapid HIV testing. Weighted data analysis was conducted using RDS-Analyst (v. 0.62).

Results: We enrolled 400 participants in Port Moresby, 352 in Lae, and 111 in Mt. Hagen. In the last six months, 73. 2\% of MSM/TGW in Port Moresby, $77.9 \%$ in Lae, and $75.9 \%$ in Mt. Hagen, had a concurrent sexual partnership. Upwards of $70 \%$ of MSM/TGW in all three cities had sex with a woman in the same period. Less than half of MSM/ TGW had ever tested for HIV. HIV prevalence among MSM/TGW was $8.5 \%$ in Port Moresby and $6.9 \%$ in Lae. Among participants in Mt. Hagen it was 1.3\%. HIV was associated with not having sex with a woman in the last six months and sexually transmitted disease symptoms in the last 12 months in Port Moresby and Lae. In Port Moresby, it was also associated with an uncut foreskin, and in Lae with earning income in the formal sector and being unable to rely on other MSM or TGW to accompany them to healthcare services.

Conclusions: The large proportion of MSM and TGW with concurrent sexual partnerships, combined with the low testing coverage, indicates strong potential for the spread of HIV. The different correlates of HIV in Port Moresby and Lae highlight the importance of conducting surveys in multiple locations and using data to develop locally appropriate interventions even within a country.

Keywords: Papua New Guinea, HIV correlates, Men who have sex with men, Transgender women, Respondent-driven, sampling.

\footnotetext{
* Correspondence: hxv8@cdc.gov

${ }^{1}$ US Centers for Disease Control and Prevention, Division of Global HIV and

Tuberculosis, 1600 Clifton Rd, NE, Atlanta, GA 30329, USA

Full list of author information is available at the end of the article
}

(c) The Author(s). 2019 Open Access This article is distributed under the terms of the Creative Commons Attribution 4.0 International License (http://creativecommons.org/licenses/by/4.0/), which permits unrestricted use, distribution, and reproduction in any medium, provided you give appropriate credit to the original author(s) and the source, provide a link to the Creative Commons license, and indicate if changes were made. The Creative Commons Public Domain Dedication waiver (http://creativecommons.org/publicdomain/zero/1.0/) applies to the data made available in this article, unless otherwise stated. 


\section{Background}

Nearly four decades since the emergence of HIV, there are still settings and populations whose HIV epidemics we know little about $[1,2]$. Papua New Guinea (PNG) is one such example. It was previously described as having a generalized epidemic. The expansion of antenatal clinic surveillance data, as well as biobehavioural surveys, have resulted in a better understanding of PNG's HIV epidemic and a consensus has emerged that with an HIV prevalence estimated at $0.9 \%$, the country is experiencing an epidemic concentrated the key populations of sex workers, men who have sex with men (MSM), and transgender women (TGW) [3-8]. The data that exist on MSM and TGW in PNG focuses on those who sell sex, rather than all MSM and TGW. This new understanding of the epidemic in PNG necessitates the collection of data on key populations to inform estimates and guide the country's HIV response.

Male-to-male sex remains illegal and highly stigmatized in PNG, hampering HIV service provision and uptake for these men. One of the first respondent-driven sampling (RDS) surveys in the world was conducted among MSM in PNG in 2005 but it did not assess HIV prevalence [7]. It did, however, highlight low condom use and experiences of discrimination among MSM. A 2010 survey of MSM had similar findings but similarly did not include HIV testing [8]. In the same year, a survey of females, males, and transgender women engaged in sex work in the capital of Port Moresby found HIV prevalence in these populations of 19.0, 8.8, 23.7\%, respectively [9]. These findings helped reorient PNG's HIV response to focus on key populations, but until now there has been little information to guide the epidemic response $[10,11]$.

Data about MSM and TGW in PNG are needed to guide the country's HIV strategy and service provision. In conjunction with the PNG National Department of Health and National AIDS Council Secretariat, we conducted a respondent-driven sampling (RDS) biobehavioural surveys (BBS) of MSM and TGW in Port Moresby to fill this information gap. Here we report on HIV prevalence and correlates of HIV infection.

\section{Methods}

\section{Community consultation}

Community consultation was undertaken with MSM and TGW in Port Moresby, Lae, and Mt. Hagen to guide survey preparation and build trust with local stakeholders. Community consultation indicated that recruiting MSM and TGW would be challenging and both populations found it acceptable to combine the two populations into one survey sample.

\section{Study population, setting, and design}

We conducted RDS BBS of MSM and TGW in Port Moresby from June to October 2016, in Lae from January to June 2017, and Mt. Hagen from August to December 2017. These cities were selected for the survey because they are the most populous and include the national capital (Port Moresby), the main economic city and port (Lae), and a city that is at the intersection of roads and natural resource extraction activities in the country (Mt. Hagen). RDS is a variant of snowball sampling that can be used to produce sampling weights and approximate a random sample [12-14]. Eligibility criteria were: age $\geq 12$ years, spoke English or Tok Pisin, born biologically male, had oral or anal sex with a male in the past 6 months, and be in possession of a valid study coupon.

\section{Recruitment}

Recruitment started with four seeds in Port Moresby, four in Lae, and five in Mt. Hagen. Twelve additional seeds were added in Port Moresby, 15 in Lae, and 4 in Mt. Hagen to facilitate recruitment. Seeds were purposely selected to create diversity with respect to: age, sexual/gender identity, place of residence, region of origin, marital status, receipt of a unique object for size estimation, and affiliation with a non-governmental or community-based organization.

\section{Data collection}

Candidate participants were screened for eligibility and those eligible were asked to provide verbal informed consent. Non-blood specimens were collected for sexually transmitted infection and tuberculosis testing after which participants engaged in a computer-assisted personal interview (Open Data Kit, Washington, US).

After the interview, participants received pre-test HIV counseling before providing written informed consent for HIV testing. Fifteen milliliters of blood was taken through venipuncture for HIV testing and, if positive by confirmatory testing, CD4 T-cell count and molecular HIV viral load testing were also conducted at the point-of-care. The PNG national algorithm for HIV testing was used: Determine HIV-1/2 (Alere, MA, USA) followed by confirmatory testing with HIV 1/2 Stat-Pak (Chembio, Medford, NY). Discordant results between the two tests were deemed inconclusive, and participants were advised to retest in 3 weeks. HIV external quality assurance panels were provided by The Royal College of Pathologists of Australasia. We used the Chembio DPP Syphilis Assay to test for syphilis (Chembio, Medford, NY). All test results were returned to participants at the end of the first study visit. HIV-positive participants were offered an escort by a peer navigator to HIV treatment services of their choosing that had been sensitized 
to work with key populations. Those with an active syphilis infection initiated treatment at the survey site and were given a referral to complete treatment. Study staff were trained to identify and refer all sexually exploited persons under the age of 18 years to partner organizations experienced in providing counseling, health, social, and other protective services to these populations.

While waiting for test results, participants in Port Moresby received 3 coupons with which to recruit peers. Midway through data collection the number of coupons was increased to 4 to increase recruitment. Participants in Lae received three coupons to recruit peers and in Mt. Hagen they received four. In all locations, participants received 45 PNG kina for their first visit (about \$14 US) and 10 PNG kina (about \$3 US) per successful recruit plus 5 PNG kina (about \$1.50 US) for transportation at their second visit. All participants were also provided with information on HIV and other sexually transmitted infections, condoms, and lubricants.

\section{Data measures}

The questionnaire used as its foundation the WHO, CDC, UNAIDS, and FHI360 Biobehavioral Survey Guidelines for Populations at Risk for HIV [15]. Interview domains included demographics, sexual history and identity, condom use, stigma, social cohesion, violence, HIV knowledge, history of sexually transmitted diseases, penile modification, internalized homophobia, and uptake of health services. The two-item Patient Health Questionnaire (PHQ-2) was used to screen for depression [16]. Internalized homophobia was defined based on responses to five questions regarding their feelings about sexual attraction to men. Comprehensive awareness of HIV was based on the United Nations Joint Programme for HIV/AIDS definition of correctly answering three questions and rejecting two myths regarding HIV [17]. Partner concurrency was defined as overlapping sexual partnerships with partners of any sex where sexual intercourse with one partner occurred between two acts of intercourse with another partner, limited to the last three sexual partners in the last six months. The full questionnaires can be found in the Additional files 1 and 2 (FSW Questionnaire and MSM TGW Questionnaire).

\section{Data analysis}

Our analysis characterizes MSM and TGW and correlates of HIV infection among these populations in each of the three survey cities. Odds ratios (OR) and 95\% confidence intervals (CI) were calculated for bivariate comparisons and a $p$-value $<0.1$ was the threshold for inclusion in multivariate analysis to identify a final model. To remain in the final model, the least significant variable was eliminated until all remaining variables were significant at the 0.05 level. Additional variables were removed to lower the relative standard error.

In Port Moresby, the full model included education, gender identity, disclosed sexual identity to non-MSM, ever cut foreskin, sex with a woman in the last 6 months, self-reported sexually transmitted disease (STD) symptoms, used the internet or mobile application to meet people, and last contact with peer outreach.

In Lae, the full model included main source of income, disclosure of sexual behaviors to non-MSM, can rely on other MSM or TGW accompany them to the doctor, experienced physical violence in the last 12 months, sex with a woman in the last 6 months, had self-reported STD symptoms, and last contact with peer outreach. No model was produced for Mt. Hagen because the actual sample size was too small and convergence was not reached for HIV [18].

Data were weighted and analyzed using RespondentDriven Sampling Analyst (RDS-A) version 0.62 (Los Angeles, CA) and SAS version 9.3 (Carey, NC). We utilized Giles' Successive Sampling Estimator in RDS-A. All data presented are RDS-adjusted population estimates unless otherwise indicated. Weights were imported from RDS-A, and survey logistic procedures were used in SAS to identify correlates of HIV infection.

\section{Ethical approval}

This survey was approved by the PNG National Department of Health's Medical Research Advisory Committee (MRAC), the Research Advisory Committee of the National AIDS Council Secretariat (RAC), the PNG Institute of Medical Research's Institutional Review Board (IRB), and the Human Research Ethics Committee at UNSW Sydney, Australia. The protocol was reviewed according to the Centers for Disease Control and Prevention's $(\mathrm{CDC})$ human research protection procedures and was determined to be research but CDC was not engaged. A letter of support was provided by Kapul Champion, the peer led civil society for sexually diverse men and transgender people.

\section{Results}

We enrolled 400 participants (354 MSM and 46 TGW) in Port Moresby, 352 in Lae (325 MSM and 27 TGW), and 111 in Mt. Hagen (104 MSM and 7 TGW). We distributed 1348 coupons in Port Moresby, 1044 in Lae, and 444 in Mt. Hagen. The longest recruitment chain in each city had 26, 19, and 10 recruitment waves, respectively.

In all three cities male identity was more common than transgender identity and the majority of MSM and TGW were between the ages of 20-29 years (Table 1). The median age was highest in Port Moresby and lowest 
Table 1 Characteristics of men who have sex with men (MSM) and transgender women (TGW) in Port Moresby, Lae and Mt. Hagen

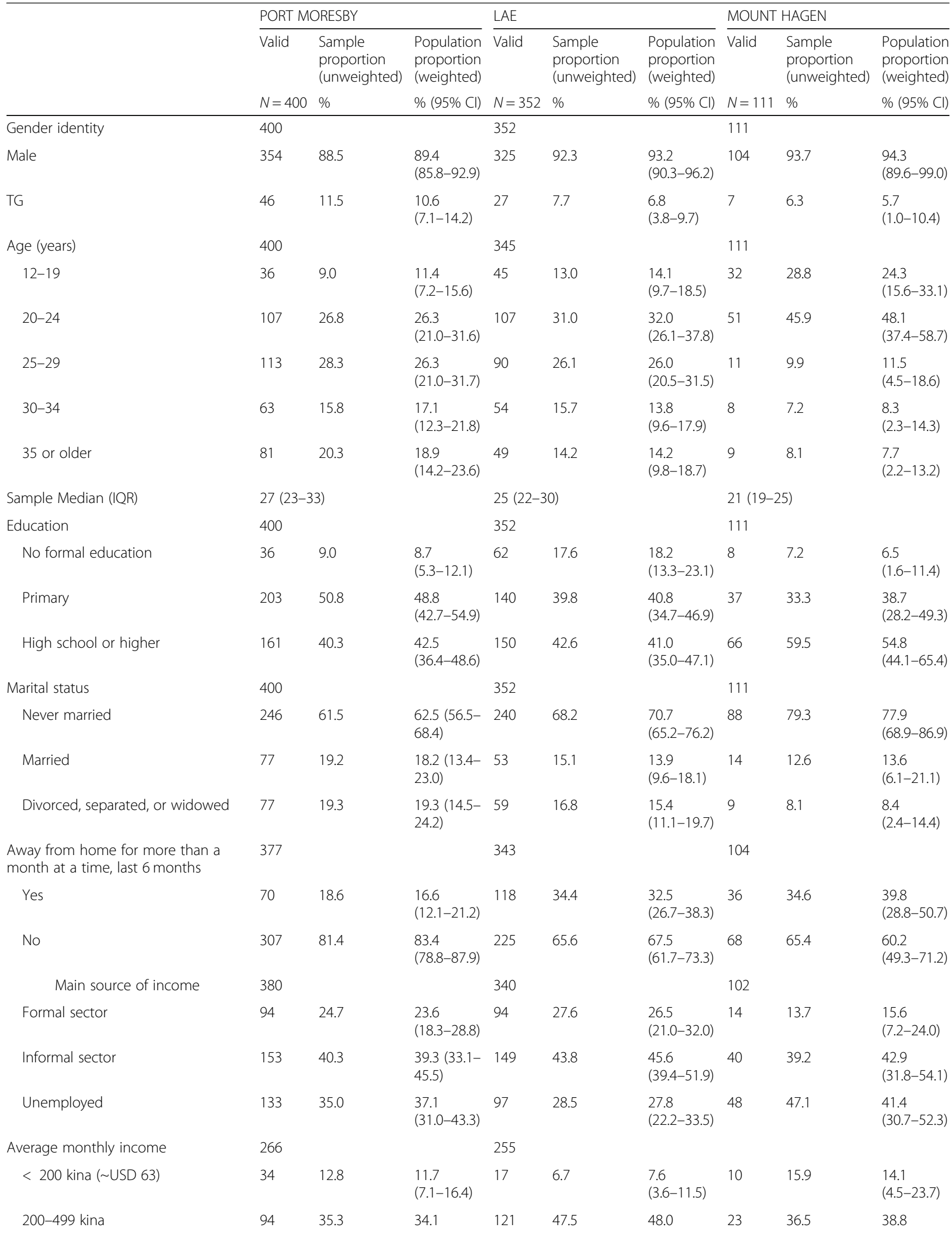


Table 1 Characteristics of men who have sex with men (MSM) and transgender women (TGW) in Port Moresby, Lae and Mt. Hagen (Continued)

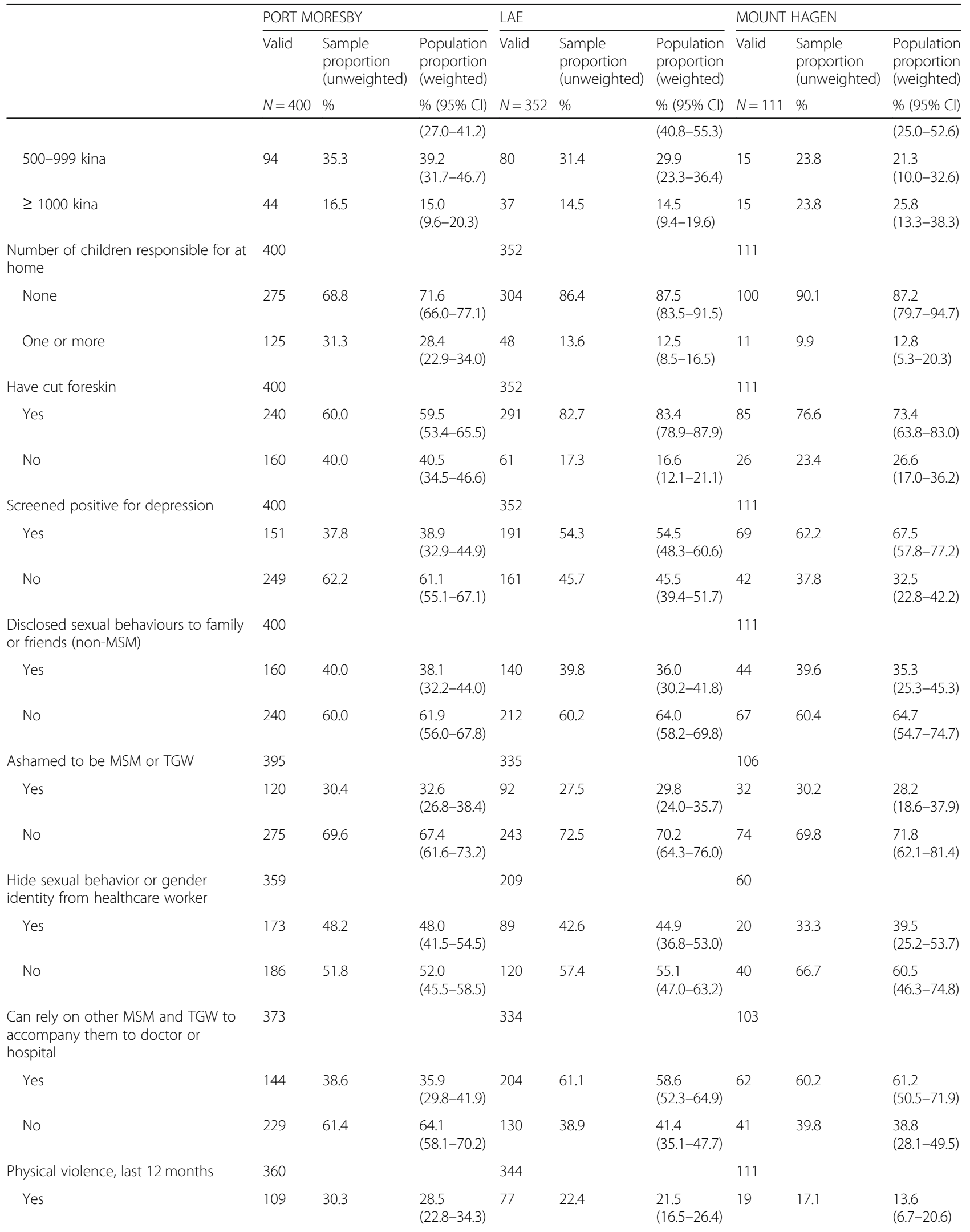


Table 1 Characteristics of men who have sex with men (MSM) and transgender women (TGW) in Port Moresby, Lae and Mt. Hagen (Continued)

\begin{tabular}{|c|c|c|c|c|c|c|c|c|c|}
\hline & \multicolumn{3}{|c|}{ PORT MORESBY } & \multicolumn{3}{|l|}{$\underline{\text { LAE }}$} & \multicolumn{3}{|c|}{ MOUNT HAGEN } \\
\hline & Valid & $\begin{array}{l}\text { Sample } \\
\text { proportion } \\
\text { (unweighted) }\end{array}$ & $\begin{array}{l}\text { Population } \\
\text { proportion } \\
\text { (weighted) }\end{array}$ & Valid & $\begin{array}{l}\text { Sample } \\
\text { proportion } \\
\text { (unweighted) }\end{array}$ & $\begin{array}{l}\text { Population } \\
\text { proportion } \\
\text { (weighted) }\end{array}$ & Valid & $\begin{array}{l}\text { Sample } \\
\text { proportion } \\
\text { (unweighted) }\end{array}$ & $\begin{array}{l}\text { Population } \\
\text { proportion } \\
\text { (weighted) }\end{array}$ \\
\hline & $N=400$ & $\%$ & $\%(95 \% \mathrm{Cl})$ & $N=352$ & $\%$ & $\%(95 \% \mathrm{Cl})$ & $N=111$ & $\%$ & $\%(95 \% \mathrm{Cl})$ \\
\hline No & 251 & 69.7 & $\begin{array}{l}71.5 \\
(65.7-77.2)\end{array}$ & 267 & 77.6 & $\begin{array}{l}78.5 \\
(73.6-83.5)\end{array}$ & 92 & 82.9 & $\begin{array}{l}86.4 \\
(79.4-93.3)\end{array}$ \\
\hline Sexual violence, last 12 months & 399 & & & 351 & & & 110 & & \\
\hline Yes & 40 & 10.0 & $\begin{array}{l}9.9 \\
(6.2-13.6)\end{array}$ & 23 & 6.6 & $\begin{array}{l}5.4 \\
(2.7-8.2)\end{array}$ & 8 & 7.3 & $\begin{array}{l}8.0 \\
(2.0-14.0)\end{array}$ \\
\hline No & 359 & 90.0 & $\begin{array}{l}90.1 \\
(86.4-93.8)\end{array}$ & 328 & 93.4 & $\begin{array}{l}94.6 \\
(91.8-97.3)\end{array}$ & 102 & 92.7 & $\begin{array}{l}92.0 \\
(86.0-98.0)\end{array}$ \\
\hline
\end{tabular}

in Mt. Hagen. MSM and TGW in Lae were less educated than in the other two cities. Between 60 and $80 \%$ had never been married in all three cities. A higher proportion of MSM and TGW in Lae and Mt. Hagen (32.5 and $39.8 \%$, respectively) had spent more than a month away from home in the last six months than in Port Moresby (16.6\%). Over half of MSM and TGW in all cities cut their foreskin.

While $38.9 \%$ screened positive for depression in Port Moresby, $54.5 \%$ did so in Lae and $67.5 \%$ in Mt. Hagen. Less than $40 \%$ of MSM and TGW in all three cities had disclosed to family or friends that they have sex with men and slightly less than one-third were ashamed to be MSM or TGW. Hiding sexual behavior or gender identity from healthcare workers was practiced by $48.0 \%$ in Port Moresby, $44.9 \%$ in Lae, and 39.5\% in Mt. Hagen. A smaller proportion of MSM and TGW in Port Moresby (35.9\%) could rely on peers to accompany them to the doctor or hospital than in Lae (58.6\%) and Mt. Hagen (61.2\%). Exposure to physical violence in the last 12 months was substantially higher in Port Moresby $(28.5 \%$ compared to $13.6 \%$ in Mt. Hagen); whereas exposure to sexual violence in the last 12 months was comparable across all three cities $(9.9 \%$ in Port Moresby, $5.4 \%$ in Lae, and $8.0 \%$ in Mt. Hagen).

Upwards of $45 \%$ of MSM and TGW first had sex with another MSM or TGW before age 20 (Table 2). MSM and TGW had at least three male sex partners in the last six months, with over half having 10 or more. The internet and mobile applications were used to find sex partners to a greater extent (42.6\%) in Mt. Hagen, where MSM and TGW are most hidden, than in the other study cities. Concurrent partnerships were engaged in by $73.2 \%$ of MSM and TGW in Port Moresby, $77.9 \%$ in Lae, and $75.9 \%$ in Mt. Hagen, and approximately three-quarters had sex with a woman in the last six months in all three cities. More MSM and TGW sold sex in the last six months in Port Moresby than Lae and Mt. Hagen (51.6\% versus 38.5 and $33.0 \%$, respectively), whereas payment to a man or TGW for sex in the last six months was similar across all cities (9.3, 12.9, and $11.7 \%$, respectively). Condom use at last anal sex with a male or transgender woman was limited at $26.9 \%$ in Port Moresby, 26.3\% in Lae, and 32.5\% in Mt. Hagen.

Comprehensive knowledge of HIV was low among MSM and TGW at $37.6 \%$ in Port Moresby, $43.8 \%$ in Lae, and $48.3 \%$ in Mt. Hagen (Table 3). Between one-quarter and half of MSM and TGW had never interacted with a peer outreach worker. While $64.4 \%$ of MSM and TGW in Port Moresby received free condoms in the last 12 months, $42.7 \%$ had in Mt. Hagen. Experiences of STD symptoms in the last 12 months were common at $27.8 \%$ in Port Moresby, $31.5 \%$ in Lae, and $19.3 \%$ in Mt. Hagen.

Less than half of MSM and TGW had ever tested for HIV (41.8\% in Port Moresby, $32.1 \%$ in Lae, and $28.7 \%$ in Mt. Hagen) and of those who had, over half in each city tested more than six months ago. Survey-related testing found HIV prevalence among MSM and TGW was $8.5 \%$ (95\% CI: 5.0-11.9) in Port Moresby and 6.9\% (95\% CI: $3.6-10.3$ ) in Lae, and $1.8 \%$ among survey participants in Mt. Hagen. ${ }^{1}$ Prevalence of active syphilis was 4.0, 8.5, and $2.5 \%$, respectively, in the three cities. Prevalence of lifetime syphilis infection was 10.1, 21.1, and $8.3 \%$, respectively (data not shown).

Among MSM and TGW in Port Moresby, correlates of HIV in multivariate analysis included not having sex with a woman in the last 6 months (adjusted odds ratio (aOR): 4.5, 95\% CI: 1.6-12.6), having self-reported uncut foreskin (aOR: 6.5, 95\% CI: 1.9-22.3), and reporting at least one symptom of an STD in the last 12 months (aOR: 6.0, 95\% CI: 2.2-16.5) (Table 4). In Lae, correlates of HIV included earning income in the formal sector (versus informal sector) (aOR: 4.7, 95\% CI: 1.2-18.3), being unable to rely on other MSM or TGW to accompany them to healthcare services (aOR: 8.5, 95\% CI: 2.429.9), not having sex with a woman in the last six months (aOR: 7.7, 95\% CI: 2.4-25.5), and experiencing 
Table 2 Sexual behaviors of men who have sex with men and transgender women in Port Moresby, Lae and Mt. Hagen

\begin{tabular}{|c|c|c|c|c|c|c|c|c|c|}
\hline & \multicolumn{3}{|c|}{ PORT MORESBY } & \multicolumn{3}{|l|}{ LAE } & \multicolumn{3}{|c|}{ MOUNT HAGEN } \\
\hline & Valid & $\begin{array}{l}\text { Sample } \\
\text { proportion } \\
\text { (unweighted) }\end{array}$ & $\begin{array}{l}\text { Population } \\
\text { proportion } \\
\text { (weighted) }\end{array}$ & Valid & $\begin{array}{l}\text { Sample } \\
\text { proportion } \\
\text { (unweighted) }\end{array}$ & $\begin{array}{l}\text { Population } \\
\text { proportion } \\
\text { (weighted) }\end{array}$ & $\overline{V a l i d}$ & $\begin{array}{l}\text { Sample } \\
\text { proportion } \\
\text { (unweighted) }\end{array}$ & $\begin{array}{l}\text { Population } \\
\text { proportion } \\
\text { (weighted) }\end{array}$ \\
\hline & $N=400$ & $\%$ & $\%(95 \%$ Cl) & $N=352$ & $\%$ & $\%(95 \% \mathrm{Cl})$ & $N=111$ & $\%$ & $\%(95 \%$ Cl) \\
\hline $\begin{array}{l}\text { Age first had anal sex } \\
\text { with a man or TG (years) }\end{array}$ & 376 & & & 332 & & & 108 & & \\
\hline $10-14$ & 33 & 8.8 & $7.1(4.2-10.0)$ & 28 & 8.4 & $7.5(4.3-10.7)$ & 2 & 1.9 & $3.0(0.0-7.1)$ \\
\hline $15-19$ & 143 & 38.0 & $37.7(31.6-43.9)$ & 123 & 37.0 & $40.7(34.4-47.1)$ & 54 & 50.0 & $47.9(37.1-58.7)$ \\
\hline $20-24$ & 108 & 28.7 & $30.3(24.4-36.2)$ & 103 & 31.0 & $29.4(23.7-35.1)$ & 36 & 33.3 & $32.9(22.7-43.2)$ \\
\hline $25-29$ & 65 & 17.3 & $17.6(12.7-22.5)$ & 45 & 13.6 & $14.5(9.8-19.0)$ & 9 & 8.3 & $10.3(3.5-17.1)$ \\
\hline 30 or older & 27 & 7.2 & $7.3(4.0-10.7)$ & 33 & 9.9 & $7.9(4.8-11.0)$ & 7 & 6.5 & $5.9(1.1-10.8)$ \\
\hline $\begin{array}{l}\text { Total number of male or } \\
\text { TGW partners in the last } \\
6 \text { months }\end{array}$ & 400 & & & 352 & & & 111 & & \\
\hline 1-2 partners & 0 & 0.0 & 0.0 & 0 & 0.0 & 0.0 & 0 & 0.0 & 0.0 \\
\hline 3-4 partners & 35 & 8.8 & $10.7(6.6-14.8)$ & 3 & 0.9 & $0.7(0.0-1.5)$ & 1 & 0.9 & $1.4(0.0-4.3)$ \\
\hline 5-9 partners & 132 & 33.0 & $32.1(26.5-37.8)$ & 119 & 33.8 & $32.1(26.4-37.8)$ & 34 & 30.6 & $26.1(17.0-35.1)$ \\
\hline 10 or more partners & 233 & 58.3 & $57.2(51.1-63.3)$ & 230 & 65.3 & $67.2(61.4-72.9)$ & 76 & 68.5 & $72.5(63.2-81.8)$ \\
\hline $\begin{array}{l}\text { Used internet or mobile } \\
\text { apps to meet partners, } \\
\text { last } 6 \text { months }\end{array}$ & 399 & & & 351 & & & 111 & & \\
\hline Yes & 85 & 21.3 & $23.2(17.9-28.4)$ & 98 & 27.9 & $24.3(19.1-29.4)$ & 45 & 40.5 & $42.6(32.0-53.2)$ \\
\hline No & 314 & 78.7 & $76.8(71.6-82.1)$ & 253 & 72.1 & 75.7 (70.6-80.9) & 66 & 59.5 & $57.4(46.8-68.0)$ \\
\hline $\begin{array}{l}\text { Partner concurrency in } \\
\text { the last } 6 \text { months }\end{array}$ & 197 & & & 187 & & & 67 & & \\
\hline Yes & 157 & 79.7 & $73.2(64.8-81.6)$ & 150 & 80.2 & $77.9(70.5-85.2)$ & 53 & 79.1 & $75.9(63.7-88.2)$ \\
\hline No & 40 & 20.3 & $26.8(18.4-35.2)$ & 37 & 19.8 & $22.1(14.8-29.5)$ & 14 & 20.9 & $24.1(11.8-36.3)$ \\
\hline $\begin{array}{l}\text { Had vaginal/anal sex } \\
\text { with a woman in the } \\
\text { last } 6 \text { months }\end{array}$ & 400 & & & 352 & & & 111 & & \\
\hline Yes & 294 & 73.5 & $72.8(67.4-78.3)$ & 302 & 85.8 & $86.8(82.8-90.9)$ & 95 & 85.6 & $84.1(76.2-91.9)$ \\
\hline No & 106 & 26.5 & $27.2(21.7-32.6)$ & 50 & 14.2 & $13.2(9.1-17.2)$ & 16 & 14.4 & $15.9(8.1-23.8)$ \\
\hline $\begin{array}{l}\text { Had a main male } \\
\text { partner, last } 6 \text { months }\end{array}$ & 378 & & & 339 & & & 103 & & \\
\hline Yes & 152 & 40.2 & $39.4(33.2-45.5)$ & 72 & 21.2 & $20.0(15.0-24.9)$ & 20 & 19.4 & $22.7(13.1-32.3)$ \\
\hline No & 226 & 59.8 & $60.6(54.5-66.8)$ & 267 & 78.8 & $80.0(75.1-85.0)$ & 83 & 80.6 & $77.3(67.7-86.9)$ \\
\hline $\begin{array}{l}\text { Condom use with main } \\
\text { male partner(s), last } 6 \\
\text { months }\end{array}$ & 152 & & & 71 & & & 20 & & \\
\hline Always & 31 & 20.4 & $20.4(12.4-28.4)$ & 17 & 23.9 & $16.8(7.1-26.5)$ & 6 & 30.0 & $32.6(7.8-57.4)$ \\
\hline Sometimes & 76 & 50.0 & $50.3(40.2-60.3)$ & 32 & 45.1 & $49.8(35.5-64.1)$ & 5 & 25.0 & $16.8(0.0-34.3)$ \\
\hline Never & 45 & 29.6 & $29.3(20.2-38.5)$ & 22 & 31.0 & $33.4(19.6-47.2)$ & 9 & 45.0 & $50.6(24.5-76.8)$ \\
\hline $\begin{array}{l}\text { Usual sexual position } \\
\text { with main male partner }\end{array}$ & 151 & & & 71 & & & 20 & & \\
\hline Receptive & 36 & 23.8 & $23.8(15.4-32.2)$ & 21 & 29.6 & $25.5(13.6-37.4)$ & 3 & 15.0 & $10.7(0.0-25.9)$ \\
\hline Insertive & 101 & 66.9 & $65.9(56.3-75.4)$ & 46 & 64.8 & $68.1(55.2-81.1)$ & 14 & 70.0 & $68.6(43.9-93.3)$ \\
\hline Both & 14 & 9.3 & $10.3(3.9-16.7)$ & 4 & 5.6 & $6.3(0.0-13.3)$ & 3 & 15.0 & $20.7(0.0-43.1)$ \\
\hline $\begin{array}{l}\text { Had a casual male } \\
\text { partner, last } 6 \text { months }\end{array}$ & 378 & & & 339 & & & 103 & & \\
\hline Yes & 216 & 57.1 & $54.8(48.4-61.1)$ & 236 & 69.6 & $66.9(60.9-72.9)$ & 68 & 66.0 & $66.4(55.9-76.8)$ \\
\hline
\end{tabular}


Table 2 Sexual behaviors of men who have sex with men and transgender women in Port Moresby, Lae and Mt. Hagen (Continued)

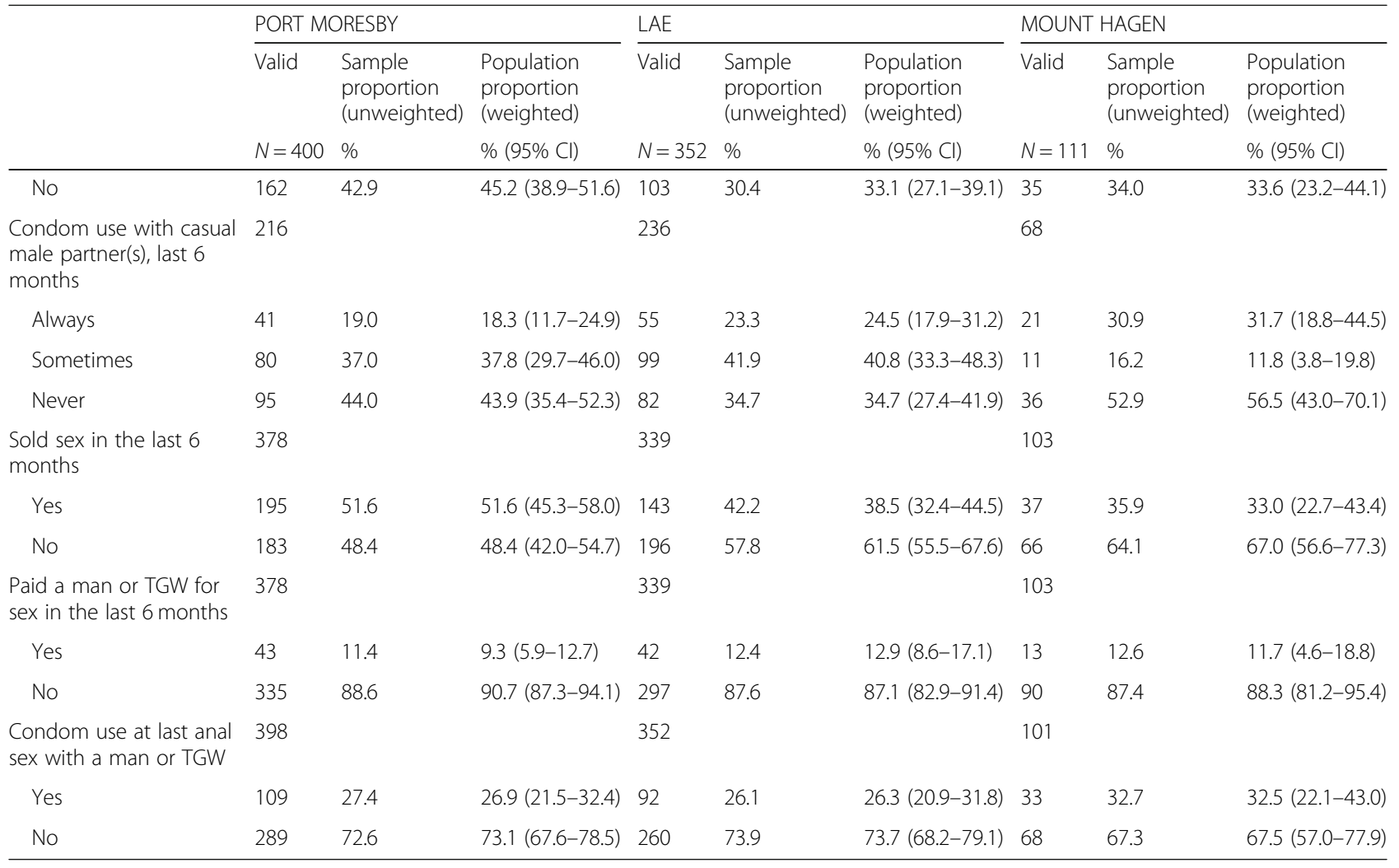

at least one symptom of an STD in the last 12 months (aOR: 4.2, 95\% CI: 1.4-13.1) (Table 5).

\section{Discussion}

Our survey is the first biobehavioral HIV survey of MSM and TGW in PNG that includes both sex workers and non-sex workers. The large proportions of MSM and TGW with concurrent sexual partnerships or who sell sex, combined with the low testing coverage and condom use at last anal sex with a male or transgender woman, suggests substantial potential for the spread of HIV among these populations and their female sexual partners.

The different correlates of HIV in Port Moresby and Lae highlight the importance of conducting surveys in multiple locations and most importantly using such data to develop locally appropriate interventions even for the same population within a country. Having an uncut foreskin is associated with greater risk of HIV in Port Moresby but there is no association in Lae. In contrast, not being able to rely on peers for accompaniment to a clinic or hospital is not associated with HIV in Port Moresby but is associated with increased risk of the disease in Lae. This may be because there are fewer HIV and sexual health services for MSM and TGW in Lae than in Port Moresby, and the prospect of accessing services alone at facilities with staff not trained to work with MSM and TGW may prove daunting. Employment in the formal sector was also associated with HIV in Lae but not in Port Moresby, suggesting the need for greater targeting of HIV prevention and testing service in Lae compared to Port Moresby. In both cities, not having sex with a woman in the last six months was associated with HIV infection. While it is important to access all MSM and TGW for HIV services, given the low engagement of MSM and TGW in PNG with outreach workers and HIV testing, prioritization of limited HIV resources to MSM and TGW who do not have sex with women could reach more people as these individuals are often most accessible to KP services.

A high prevalence of sexually transmitted infections has been well documented in PNG, and we similarly documented a high prevalence of self-reported STD symptoms among MSM and TGW [19, 20]. Though active syphilis infection was not associated with HIV, in both Port Moresby and Lae, HIV was associated with having at least one STD symptom in the last 12 months. As STI can contribute to both the transmission and acquisition of HIV, those seeking treatment for STD symptoms should routinely be offered HIV testing $[21,22]$.

The lower proportion of MSM and TGW traveling outside of Port Moresby compared to other cities is likely due to the fact that Port Moresby is not connected 
Table 3 HIV knowledge, uptake of HIV services among, and HIV and syphilis prevalence men who have sex with men and transgender women in Port Moresby, Lae and Mt. Hagen

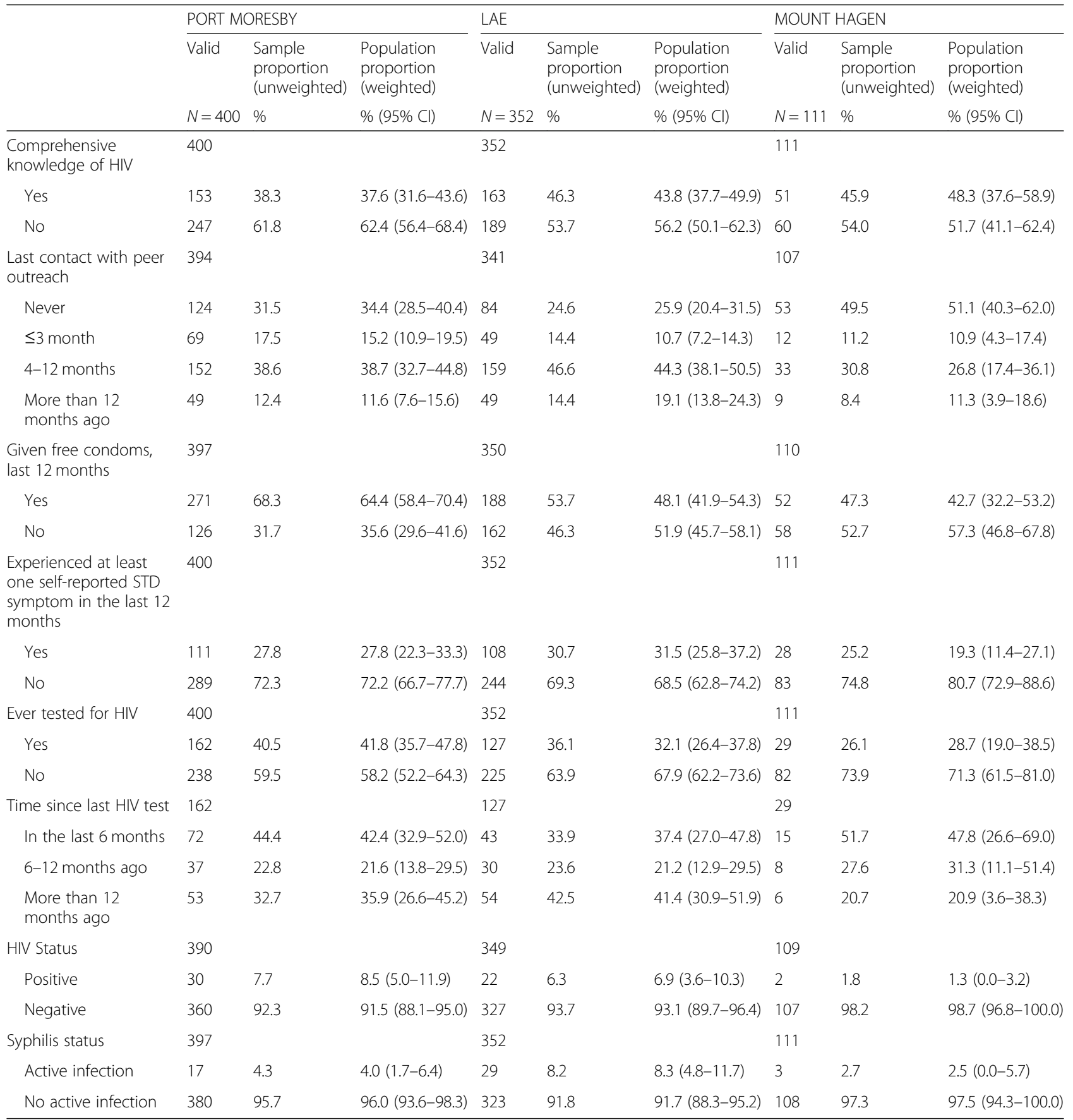

to the rest of the country by road, whereas Lae and Mt. Hagen are on the main highway. This may also lend itself to preventing the spread of HIV from the capital to Lae and Mt. Hagen.

As the use of the internet and mobile applications to meet sexual partners has rapidly expanded in PNG and will likely continue to do so, these media platforms may be an effective way of reaching MSM and TGW with information about HIV and services. The relative recency (last 12 months) of interaction of MSM and TGW in Port Moresby and Lae with peer outreach workers suggests the potential for community-based HIV testing or provider-assisted self-testing.

Our findings are limited by the cross-sectional nature of our study and the low sample size in Mt. Hagen which we believe is due to the particularly heteronormative culture 
Table 4 Predictors of being HIV-positive among men who have sex with men and transgender women in Port Moresby

\begin{tabular}{|c|c|c|c|c|c|}
\hline & $\mathrm{N}$ & Bivariate OR (95\% Cl) & $p$-value & Multivariable aOR (95\% Cl) & $p$-value \\
\hline Age (years) & 390 & & 0.9606 & & \\
\hline $12-24$ & & Ref & & & \\
\hline $25-29$ & & $1.02(0.32-3.26)$ & & & \\
\hline $30+$ & & $1.15(0.41-3.23)$ & & & \\
\hline Gender identity & 390 & & $<0.0001$ & & \\
\hline Male & & Ref & & & \\
\hline TG & & $9.61(3.64-25.34)$ & & & \\
\hline Education & 390 & & & & \\
\hline No formal education & & Ref & & & \\
\hline Primary & & $4.34(1.06-17.84)$ & & & \\
\hline High school or higher & & $2.18(0.80-5.92)$ & & & \\
\hline Main source of income & 370 & & & & \\
\hline Formal & & $2.03(0.65-6.31)$ & & & \\
\hline Informal & & Ref & & & \\
\hline Unemployed & & $1.10(0.34-3.55)$ & & & \\
\hline Marital status & 390 & & & & \\
\hline Never married & & Ref & & & \\
\hline Married & & $0.53(0.13-2.14)$ & & & \\
\hline Divorced, separated, or widowed & & $0.70(0.18-2.71)$ & & & \\
\hline Disclosed sexual behaviours to family or friends (non-MSM) & 390 & & & & \\
\hline Yes & & Ref & & & \\
\hline No & & $0.37(0.15-0.92)$ & & & \\
\hline Used internet or mobile apps to meet partners, last 6 months & 389 & & 0.0007 & & \\
\hline Yes & & $4.85(1.95-12.04)$ & & & \\
\hline No & & Ref & & & \\
\hline Had vaginal/anal sex with a woman in the last 6 months & 390 & & 0.0057 & & 0.0544 \\
\hline Yes & & Ref & & Ref & \\
\hline No & & $7.88(2.96-21.03)$ & & $4.49(1.60-12.60)$ & \\
\hline Have cut foreskin & 390 & & 0.0002 & & 0.0143 \\
\hline Yes & & Ref & & Ref & \\
\hline No & & $10.54(3.06-36.36)$ & & $6.49(1.89-22.25)$ & \\
\hline Experienced at least one self-reported STD symptom in the last 12 months & 390 & & 0.0002 & & 0.0179 \\
\hline Yes & & $6.02(2.33-15.55)$ & & $5.95(2.15-16.46)$ & \\
\hline No & & Ref & & Ref & \\
\hline Last contact with peer outreach & 384 & & 0.0399 & & \\
\hline Never & & $0.41(0.10-1.63)$ & & & \\
\hline$\leq 3$ months & & $2.64(0.92-7.55)$ & & & \\
\hline 4-12 months & & Ref & & & \\
\hline More than 12 months ago & & $0.90(0.16-4.93)$ & & & \\
\hline
\end{tabular}

of this highlands city. Given that the lack of legal protections for MSM and TGW (which do not exist in PNG) are associated with higher HIV prevalence in a global meta-analysis and that HIV prevalence in the general population is highest in Mt. Hagen, we suspect that our finding of $1.8 \%$ prevalence among survey participants is an underestimate [23]. As interview data were self-reported in face-to-face interviews, there may be some response bias. The use of audio-computer assisted self-interviews rather than 
Table 5 Predictors of being HIV-positive among men who have sex with men and transgender women in Lae

\begin{tabular}{|c|c|c|c|c|c|}
\hline & $\mathrm{N}$ & Bivariate OR (95\% Cl) & $p$-value & Multivariable aOR $(95 \% \mathrm{Cl})$ & $p$-value \\
\hline Age (years) & 342 & & 0.1707 & & \\
\hline $12-24$ & & Ref & & & \\
\hline $25-29$ & & $2.34(0.61-8.94)$ & & & \\
\hline $30+$ & & $3.14(0.93-10.57)$ & & & \\
\hline Gender identity & 349 & & 0.8043 & & \\
\hline Male & & Ref & & & \\
\hline TG & & $1.19(0.30-4.78)$ & & & \\
\hline Education & 349 & & 0.6174 & & \\
\hline No formal education & & Ref & & & \\
\hline Primary & & $1.95(0.28-13.64)$ & & & \\
\hline High school or higher & & $2.46(0.39-15.41)$ & & & \\
\hline Main source of income & 337 & & 0.0405 & & 0.0312 \\
\hline Informal sector & & Ref & & Ref & \\
\hline Formal sector & & $5.08(1.33-19.39)$ & & $4.66(1.19-18.28)$ & \\
\hline Unemployed & & $1.85(0.42-8.09)$ & & $0.99(0.20-4.89)$ & \\
\hline Marital status & 349 & & 0.1336 & & \\
\hline Never married & & Ref & & & \\
\hline Married & & $1.90(0.52-6.94)$ & & & \\
\hline Divorced, separated, or widowed & & $0.18(0.02-1.45)$ & & & \\
\hline Have cut foreskin & 352 & & 0.6639 & & \\
\hline Yes & & Ref & & & \\
\hline No & & $1.30(0.39-4.30)$ & & & \\
\hline Can rely on other MSM/TGW to accompany them to doctor or hospital & 332 & & 0.0050 & & 0.0010 \\
\hline Yes & & Ref & & Ref & \\
\hline No & & $4.57(1.59-13.16)$ & & $8.47(2.40-29.90)$ & \\
\hline Had vaginal/anal sex with a woman in the last 6 months & 349 & & 0.0042 & & 0.0008 \\
\hline Yes & & Ref & & Ref & \\
\hline No & & $7.88(2.96-21.03)$ & & $7.74(2.35-25.53)$ & \\
\hline Experienced at least one self-reported STD symptom in the last 12 months & 349 & & 0.0310 & & 0.0131 \\
\hline Yes & & $3.18(1.11-9.11)$ & & $4.21(1.36-13.09)$ & \\
\hline No & & Ref & & Ref & \\
\hline Last contact with peer outreach & 338 & & 0.0432 & & \\
\hline Never & & $0.52(0.10-2.84)$ & & & \\
\hline$\leq 3$ months & & $0.33(0.08-1.38)$ & & & \\
\hline 4-12 months & & Ref & & & \\
\hline More than 12 months ago & & $2.52(0.76-8.41)$ & & & \\
\hline
\end{tabular}

face-to-face interviews may have helped decrease this bias [24].

\section{Conclusions}

Our survey was able to reach MSM and TGW that were not engaged in HIV services, revealing that MSM and TGW will access HIV services provided in a safe, affirming environment, providing further evidence to guide service providers and policy makers. As the first HIV biobehavioral survey in PNG among MSM and TGW, this study reveals the substantial vulnerabilities and HIV risks of these populations in PNG and their limited access to and uptake of routine HIV services. Without action, HIV prevalence stands to increase among MSM and TGW in PNG. Addressing the HIV epidemic in PNG will require continued and expanded engagement with MSM and TGW across the country, respecting and responding to their different needs and vulnerabilities, 
and moving beyond a once size fits all approach to these population in PNG.

\section{Endnotes}

${ }^{1}$ Prevalence in Port Moresby and Lae is weighted and represents all MSM and TGW. Given the small sample size in Mt. Hagen, we report only on prevalence among survey participants.

\section{Additional files}

Additional file 1: FSW Questionnaire, FSW Questionnaire, Quantitative interview questionnaire used with FSW participants. (DOCX $100 \mathrm{~kb}$ )

Additional file 2: MSM TGW Questionnaire, MSM/TGW questionnaire, Quantitative interview questionnaire used with MSM/TGW participants. (DOCX $112 \mathrm{~kb})$

\section{Abbreviations}

aOR: Adjusted Odds Ratio; BBS: Biobehavioral survey; Cl: Confidence Interval; MSM: Men who have sex with men; OR: Odds Ratio; PHQ-2: Patient Health Questionnaire-2; PNG: Papua New Guinea; RDS: Respondent-driven sampling; RDS-A: Respondent-Driven Sampling-Analyst; STD: Sexually transmitted disease; TGW: Transgender women

\section{Acknowledgements}

We want to thank the survey participants for their collaboration and support for this survey. We are grateful to Kapul Champions for their ongoing support and engagement with the study and its findings.

\section{Funding}

We want to thank the survey participants for their collaboration and support for this survey. We are grateful to Kapul Champions for their ongoing support and engagement with the study and its findings. This project has been supported by the Government of Australia, the Global Fund to Fight AIDS, TB and Malaria, and the President's Emergency Plan for AIDS Relief (PEPFAR) through the Centers for Disease Control and Prevention (CDC) under the terms of Cooperative Agreement Number 1 U2G GH001531-01 to Cardno. This publication was also supported by CDC under the terms of Cooperative Agreement Number NU2GGH002093-01-00 to the Public Health Institute. CDC staff were involved in the design and oversight of this study as well as data analysis and interpretation. Neither the Government of Australia nor the Global Fund to Fight AIDS, TB and Malaria were involved.

\section{Availability of data and materials}

The datasets used and/or analysed during the current study are available from the corresponding author on reasonable request.

\section{Authors' contributions}

$\mathrm{AJH}$ and $\mathrm{AKH}$ designed the study and conceived of the manuscript. SGB and AJV led the biomarker component of the study. KC, DW, and AJH analyzed the data. AAK and BW supervised the study which was implemented by BW, $R N, J G, S P, M K, P H, H A, R N B, J N$, and SA. Technical support was provided by ND and JMK. AJH and KC contributed substantially to the writing of the manuscript, SC provided technical feedback on an early draft. All authors reviewed and approved the manuscript.

\section{Ethics approval and consent to participate}

This survey was approved by the PNG National Department of Health's Medical Research Advisory Committee (MRAC), the Research Advisory Committee of the National AIDS Council Secretariat (RAC), the PNG Institute of Medical Research's Institutional Review Board (IRB), and the Human Research Ethics Committee at UNSW Sydney, Australia. The protocol was reviewed according to the Centers for Disease Control and Prevention's (CDC) human research protection procedures and was determined to be research but CDC was not engaged. A letter of support was provided by Kapul Champion, the peer led civil society for sexually diverse men and transgender people. Verbal informed consent was provided for all aspects of the study save for HIV testing, for which written informed consent was obtained per PNG national policy. The above referenced ethics committees approved the procedure for obtaining verbal consent. The provision of verbal consent was documented by the study staff person (Coupon Manager) who signed the consent form. Verbal consent was obtained over written consent as the name on the consent form would be the only personal identifier linking participants to the study. Written permission to participate was not obtained from the parents/guardians of the minors included in this study because the study's populations are stigmatized for their behaviors and obtaining parent/guardian permission to participate would put the individuals at risk of violence, stigmatization, or harassment from their parent/guardian. The above referenced ethics committees approved this consent procedure for minors.

\section{Consent for publication}

Not applicable.

\section{Competing interests}

The authors declare that they have no competing interests.

\section{Publisher's Note}

Springer Nature remains neutral with regard to jurisdictional claims in published maps and institutional affiliations.

\section{Author details}

${ }^{1}$ US Centers for Disease Control and Prevention, Division of Global HIV and Tuberculosis, 1600 Clifton Rd, NE, Atlanta, GA 30329, USA. ²Kirby Institute, UNSW Sydney, Wallace Wurth Building, High St, Kensington, NSW 2052, Australia. ${ }^{3}$ Papua New Guinea Institute of Medical Research, Homat Street, Goroka, Eastern Highlands Province 441, Papua New Guinea. ${ }^{4}$ Papua New Guinea National Department of Health, AOPI Centre, Waigani Drive, P O Box 807, Waigani, Port Moresby, National Capital District 131, Papua New Guinea. ${ }^{5}$ University of Ghent, Sint-Pietersnieuwstraat 25, 9000 Ghent, East Flanders, Belgium.

Received: 12 December 2018 Accepted: 7 May 2019

Published online: 22 May 2019

\section{References}

1. Quinn TC, Mann JM, Curran JW, Piot P. AIDS in Africa: an epidemiologic paradigm. 1986. Bull World Health Organ. 2001;79(12):1159-67.

2. Brunet JB, Ancelle RA. The international occurrence of the acquired immunodeficiency syndrome. Ann Intern Med. 1985;103(5):670-4.

3. UNAIDS. Papua New Guinea I UNAIDS 2017 [Available from: http://www. unaids.org/en/regionscountries/countries/papuanewguinea/.

4. Papua New Guinea Natinoal AIDS Council Secretariat. Papua New Guinea HIV Prevalence 2012 Estimates. Port Moresby; 2013.

5. Altman D, Aggleton P, Williams M, Kong T, Reddy V, Harrad D, et al. Men who have sex with men: stigma and discrimination. Lancet 2012:380(9839):439-45.

6. Baral SD, Poteat T, Strömdahl S, Wirtz AL, Guadamuz TE, Beyrer C. Worldwide burden of HIV in transgender women: a systematic review and meta-analysis. Lancet Infect Dis. 2013;13(3):214-22.

7. Yeka W, Maibani-Michie G, Prybylski D, Colby D. Application of respondent driven sampling to collect baseline data on FSWs and MSM for HIV risk reduction interventions in two urban centres in Papua New Guinea. J Urban Health. 2006:83(6 Suppl):i60-72.

8. Family Health International. Behaviors, Knowledge, Exposure to Interventions: Report from a Behavioral Surveillance Survey, Port Moresby, Papua New Guinea. Bangkok; 2011. Available from: https://www.fhi360.org/ resource/behaviors-knowledge-and-exposure-interventions-reportbehavioral-surveillance-survey-port.

9. Kelly A, Kupul M, Man WYN, Nosi S, Lote N, Rawstorne P, Halim G, Ryan C, Worth H. Askim na save (Ask and understand): People who sell and/or exchange sex in Port Moresby. Key Quantitative Findings. Sydney: Papua New Guinea Institute of Medical Research and the University of New South Wales; 2011

10. Secretariat PNGNAC. Papua New Guinea national HIV and AIDS strategy 2011-2015. National Department of Health: Port Moresby; 2010.

11. PNG Mid Term Review Team. Mid Term Review of Papua New Guinea HIV Strategy (2011-2015). 2013 
12. Heckathorn DD. Respondent-driven sampling: a new approach to the study of hidden populations. Soc Probl. 1997;44:174-99.

13. Heckathorn DD. Snowball versus respondent-driven sampling. Sociol Methodol. 2011:41(1):355-66.

14. Malekinejad M, Johnston LG, Kendall C, Kerr LR, Rifkin MR, Rutherford GW. Using respondent-driven sampling methodology for HIV biological and behavioral surveillance in international settings: a systematic review. AIDS Behav. 2008;12(4 Suppl):S105-30.

15. WHO, CDC, UNAIDS, FHI 360. Biobehavioral survey guidelines for Populations at Risk for HIV. Geneva: World Health Organization; 2017.

16. Kroenke K, Spitzer RL, Williams JB. The patient health Questionnaire-2: validity of a two-item depression screener. Med Care. 2003;41(11):1284-92.

17. UNAIDS. Global AIDS response progress reporting 2014: construction of core indicators for monitoring the 2011 United Nations political declaration on HIV and AIDS. Geneva; 2014. Available from: http://files.unaids.org/en/ media/unaids/contentassets/documents/document/2014/GARPR_2014_ guidelines_en.pdf.

18. Gile KJ, Johnston LG, Salganik MJ. Diagnostics for Respondent-driven Sampling. J R Stat Soc Ser A Stat Soc. 2015;178(1):241-69.

19. Vallely LM, Toliman P, Ryan C, Rai G, Wapling J, Tomado C, et al. Prevalence and risk factors of chlamydia trachomatis, Neisseria gonorrhoeae, Trichomonas vaginalis and other sexually transmissible infections among women attending antenatal clinics in three provinces in Papua New Guinea: a cross-sectional survey. Sex Health. 2016;13(5):420-7.

20. Vallely A, Page A, Dias S, Siba P, Lupiwa T, Law G, et al. The prevalence of sexually transmitted infections in Papua New Guinea: a systematic review and meta-analysis. PLoS One. 2010;5(12):e15586.

21. Cohen M. Sexually transmitted diseases enhance HIV transmission: no longer a hypothesis. Lancet. 1998;351(Suppl 3):5-7.

22. Freeman EE, Weiss HA, Glynn JR, Cross PL, Whitworth JA, Hayes RJ. Herpes simplex virus 2 infection increases HIV acquisition in men and women: systematic review and meta-analysis of longitudinal studies. Aids. 2006:20(1):73-83.

23. Oldenburg CE, Perez-Brumer AG, Reisner SL, Mayer KH, Mimiaga MJ, Hatzenbuehler ML, et al. Human rights protections and HIV prevalence among MSM who sell sex: Cross-country comparisons from a systematic review and meta-analysis. Glob Public Health. 2018:13(4):414-25.

24. Adebajo S, et al. Comparison of audio computer assisted self-interview and face-to-face interview methods in eliciting HIV-related risks among men who have sex with men and men who inject drugs in Nigeria. PLoS One. 2014:9(1):e81981.

Ready to submit your research? Choose BMC and benefit from:

- fast, convenient online submission

- thorough peer review by experienced researchers in your field

- rapid publication on acceptance

- support for research data, including large and complex data types

- gold Open Access which fosters wider collaboration and increased citations

- maximum visibility for your research: over $100 \mathrm{M}$ website views per year

At $\mathrm{BMC}$, research is always in progress.

Learn more biomedcentral.com/submissions 